\title{
Revisionismos de relações com os Estados Unidos e suas variáveis nos governos progressistas da América do Sul
}

Revisionism of relations with the United States and its variables in progressive governments in South America

http://dx.doi.org/10.1590/0034-7329201400110

LEONARDO VALENTE MONTEIRO*

Rev. Bras. Polít. Int. 57 (1): 177-196 [2014]

\section{Introdução}

Após a onda de eleições de governos progressistas a partir de 1999, e no decorrer da primeira década do século 21, as políticas externas da América do Sul passaram por mudanças consideráveis nas relações com os Estados Unidos. Historicamente, os países da região sempre oscilaram os pêndulos de suas relações com Washington entre momentos de alinhamento e períodos de orientações que tentavam dar tom mais independente às suas diplomacias, apesar de, em amplitude e intensidades, bem distintas do que passou a ocorrer nos últimos 13 anos.

As políticas do subcontinente para a grande potência nem sempre caminharam em bloco, apesar de muitas vezes condicionantes sistêmicas (como o neoliberalismo pós Guerra-Fria dos anos 1990) terem empurrado praticamente toda a região para comportamentos muito semelhantes. Após os anos 2000, a tendência do movimento conjunto do período anterior se repetiu, só que na direção contrária. O fracasso do modelo econômico liberalizante, as eleições de governos progressistas em quase todos os países da região, a política externa do governo norte-americano de George W. Bush pós 11 de setembro e o decorrente distanciamento norteamericano da América Latina resultaram em processos de revisão de relaçôes com os Estados Unidos em quase todos os Estados sul-americanos. Movimentos, no entanto, não raro apontados como se fossem um só, quase sempre classificado como de forte tom oposicionista. Trata-se, contudo, de um reducionismo diante de uma onda semelhante em seus aspectos gerais, mas com políticas que se comportavam em diferentes gradações e com distintas finalidades específicas.

* Universidade Federal do Rio de Janeiro (UFRJ), Rio de Janeiro, RJ, Brasil (leonardo.lvalente@gmail.com). 
O objetivo deste artigo, portanto, é destacar e analisar os diferentes tipos de política revisionista, e suas gradaçôes, desenvolvidos pelos governos progressistas da América do Sul em relação aos Estados Unidos nos últimos 13 anos. Para isso, tem-se como ponto de partida conceitos fundamentais para o melhor entendimento sobre o comportamento dos países, não somente da região, mas de toda a periferia do sistema internacional, em relação à grande potência: "revisionismo periférico", de Cesar Guimarães (2008), e "confrontação autônoma" e "confrontação antagônica", ambos de Helio Jaguaribe (1986). Foi a partir dos desdobramentos desses conceitos que um modelo teórico com diferentes tipos de política revisionista periférica pode ser elaborado, permitindo uma espécie de "sintonia fina" de classificações das políticas externas do período. Compreender essas diferenças torna-se fundamental para uma análise mais densa sobre as relações da América do Sul com os Estados Unidos no início do século 21.

Foram analisados todos os governos da região no período. No entanto, um destaque mais aprofundado foi dado aos casos de Venezuela, por ter inaugurado a fase revisionista pós-neoliberal na América do Sul, e Brasil, por ter sido elemento chave na liderança regional, tanto no apoio aos governos de orientação revisionista eleitos, quanto na busca pela moderação de suas políticas em relação aos Estados Unidos.

\section{Os diferentes revisionismos de periferia sul-americanos}

Ao chegar ao poder com a ideia de refundar a República e romper com as antigas estruturas internas que controlavam a Venezuela, o presidente Hugo Chávez também assumiu que a orientação da política externa de seu país não poderia ser mais a mesma dos anos 1980 e 1990, aliada quase incondicional dos Estados Unidos nessas duas décadas. Eleito em 1999, o novo governo se configurou como uma espécie de balão de ensaio do modelo progressista (que pouco tempo depois viraria tendência na região), em meio a uma América do Sul ainda dominada por governos de direita e de centro-direita, compromissados com o modelo de integração hemisférica a partir de blocos comerciais orientados pelo "regionalismo aberto", e ideologicamente muito próximos aos Estados Unidos, que por sua vez vivenciavam o auge do "momento unipolar" nas relaçôes internacionais, fruto ainda dos primeiros momentos pós-Guerra Fria.

Chávez chegou a Miraflores em um período em que os dois grandes da América do Sul, Brasil e Argentina, ainda viviam seus momentos finais do capítulo neoliberal dos anos 1990. A Argentina, à beira do precipício econômico de onde cairia violentamente em 2000, insistia até então em uma política externa que ficou conhecida como "Realismo periférico", denominação criada por Carlos Escudé (1992), baseada na antiga doutrina realista, e que tem nas relaçôes de poder a partir de suas assimetrias a base principal do relacionamento entre os Estados. 
A visão argentina dominante na época considerava que o alinhamento ao Norte (em sua visão histórica característica da diplomacia brasileira) teria sido a receita do Brasil para a obtenção de benefícios. Por isso, o estabelecimento de uma relação de dependência consciente da periferia em relação ao centro, a partir de uma particular interpretação da política de prudência do Realismo, era o mais sensato comportamento para a obtenção de vantagens.

O Brasil passava no mesmo momento também por orientação neoliberal, porém em tom diferente. Ainda assim, apesar de não tão radical quanto o modelo argentino, configurava-se em um alinhamento com a grande potência, postura muito distante das orientações que começavam a ser consolidadas em Caracas, como afirma Cesar Guimarães (2008).

No Brasil da mesma época, e especialmente sob o presidente Fernando Henrique Cardoso, o tom é diverso, pleno de matizes e nuanças. Supõe-se que a realidade do mundo é de "polaridades indefinidas" (o conceito aparece em influente texto de Gélson Fonseca e Celso Lafer) e essa sugestão de fluidez introduz algo como "um ajuste das relações com os Estados Unidos que combina postura mais flexível como premissas anteriores de uma política externa autônoma" (aqui parafraseio formulações de Monica Hirst). [...] Para não poucos observadores, internos e externos, críticos ou adeptos, o "momento unipolar" parecia então o melhor descritor das relações internacionais do fim do século. Mas, as "polaridades indefinidas" da original formulação, se empiricamente frágeis, foram suficientes para um alinhamento que se mostrava crítico, cauteloso sem dúvida, mas alinhamento, não obstante tudo isso. (Guimarães 2008, 241).

Foi na Venezuela sob o governo de Hugo Chávez que se pôs em prática a primeira política externa revisionista da América do Sul nos anos 2000. Política esta, segundo Guimarães, a partir de uma "proposta simétrica e inversa” à aquiescência pragmática dos anos 1990 (2008, 234). Trata-se, em sua visão, do realismo periférico às avessas, convertido no que denominou como "revisionismo periférico", uma revisão de política de um país de periferia em relação à potência, calcada na clara condição assimétrica de relações, e obviamente repleta de limitações, mas com o propósito de reverter antigos alinhamentos cujos benefícios, ao contrário do que se supunha anteriormente, não foram grandes o suficiente para compensar as grandes crises econômicas e sociais decorrentes.

Tanto o realismo periférico quanto o revisionismo periférico utilizam os fundamentos realistas sobre as estruturas de poder a partir da dinâmica periferiapotência e não potência-periferia, este último sentido o corrente nessa tradição teórica em praticamente todos os estudos das relações internacionais. Enquanto o Realismo Periférico pressupóe a busca de benefícios a partir da constatação inequívoca da assimetria de poder, e do alinhamento, o revisionismo periférico 
se orienta a partir dessa mesma assimetria de poder, só que busca os benefícios a partir de uma política opositora ao status quo. Enquanto o Realismo Periférico aposta suas fichas na premissa estruturalista de manutenção sistêmica de poder, o revisionismo periférico se prende a outro fundamento realista: o de que o sistema internacional, constituído por atores unitários, possui tendência à multipolaridade, em detrimento de uma unipolaridade quase sempre frágil e instável.

O revisionismo consiste aqui em tomar a unipolaridade como "status quo" insustentável e/ou insuportável, e que supôe certo tipo, algo aguerrido, de unidade sul-americana, composta com alianças externas pertinentes. (Guimarães 2008, 244).

Apesar do movimento claramente contrário à unipolaridade e do foco na unidade sul-americana em prol de um sistema multipolar, o revisionismo periférico que se iniciou na Venezuela se espalhou pela região com posturas, gradaçôes e objetivos diferentes, formando uma onda revisionista regional formada por diferentes revisionismos. A chegada de Luiz Inácio Lula da Silva à Presidência do Brasil trouxe a adoção de uma política revisionista - porém com tom marcado pela moderação -, e posteriormente veio a radicalização do discurso de confrontação de Hugo Chávez em relação aos Estados Unidos após 2002, e também vieram os revisionismos desenvolvidos pelos governos de Néstor Kischner, na Argentina, Evo Morales, na Bolívia, Rafael Correa, no Equador, e Tabaret Vásquez, no Uruguai, que, apesar de semelhantes em suas propostas mais profundas, tornaram-se diferentes quanto aos métodos e adaptados às condicionantes estruturais de cada um desses países em suas tentativas de mudarem os rumos de suas relações com os Estados Unidos.

Antes que os movimentos dos anos 2000 se caracterizassem como uma tendência, Helio Jaguaribe (1986) já havia tido a sensibilidade de captar a diferença entre comportamentos revisionistas de periferia, especialmente na América do Sul. De maneira geral, ele dividiu esse tipo de comportamento político em dois grupos: as políticas de "confrontação autônoma" e as políticas de "confrontação antagônica”. O autonomismo, em sua visão, se aproveita das benesses do tempo, é firme em seus propósitos sem se esquecer da política da prudência, não deseja mudanças calcadas apenas pelo imediatismo e exerce a independência nas açooes de forma clara, porém discreta sempre que possível. Já o antagonismo tem um caráter imediatista, baseia-se em grande parte na confrontação, especialmente, mas não exclusivamente retórica, tem como estratégia a oposição clara em todos os níveis e tenta convertê-la em política internacional de prestígio.

Enquanto Cesar Guimarães subqualifica uma orientação política, o revisionismo de relações, particularizando-o como periférico, Jaguaribe aprofunda as diferenciações de postura dentro dessa orientação. Autonomismo e antagonismo 
são posturas diferentes dentro de uma mesma orientação, que pode ser classificada como revisionista e periférica. A reflexão a partir desses conceitos de forma conjunta permite um desdobramento de categorias de comportamentos revisionistas, com diferentes gradações. Isso, por sua vez, possibilita uma melhor categorização do que foi desenvolvido em diferentes países, e também uma reflexão mais densa sobre a diversidade dessas relações estabelecidas pelos países da região em relação aos Estados Unidos, sem perder a noção do processo regional em seu nível macro. Tal desdobramento é ilustrado na Figura 1.

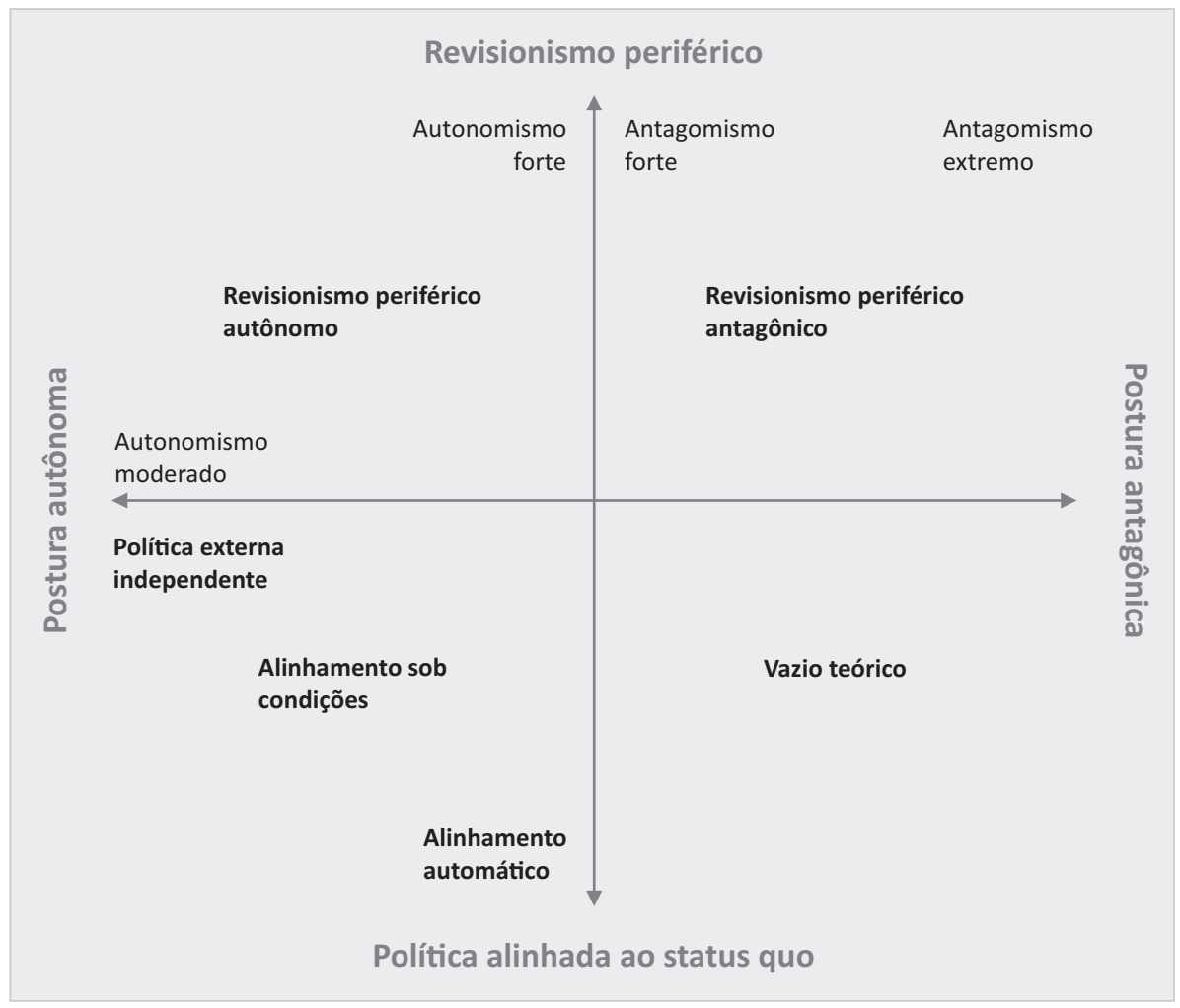

Figura 1. Categorias de comportamentos revisionistas.

$\mathrm{Na}$ figura, o eixo vertical representa a orientação da política externa, na extremidade superior o Revisionismo Periférico e na extremidade inferior a política totalmente alinhada ao status quo. $\mathrm{O}$ eixo horizontal representa a postura da política externa adotada, à esquerda do leitor está a autônoma, e, à direita, a antagônica. A orientação reflete os fundamentos básicos da política externa, suas forças motrizes em prol de um posicionamento; já a postura pode ser interpretada como uma espécie de "equalização" dessa orientação, que tom ela toma para 
sua implementação. Trata-se do tempero, importante componente, que pode tornar uma receita insossa, na medida certa ou apimentada demais, com todas as consequências de cada um desses resultados.

A combinação dos dois eixos geram quatro quadrantes onde podemos posicionar diferentes formas de relacionamento da periferia com o centro. No quadrante inferior, à esquerda, temos o espaço que vai desde a política mais alinhada ao status quo até uma política já bem distante do alinhamento, porém ainda não revisionista. Nesse campo, podemos identificar o "alinhamento automático", o "alinhamento sob condiçôes" e a "política externa independente". O quadrante superior, à esquerda do leitor, é o campo que combina a orientação revisionista à postura autônoma, compondo desde um "revisionismo periférico autônomo moderado" a um "revisionismo periférico autônomo forte", este na fronteira com o antagonismo. Já o quadrante superior à direita combina a orientação revisionista com a postura antagônica, resultando desde um "revisionismo periférico antagônico forte" até um "revisionismo periférico antagônico extremo". O quadrante inferior à direita do leitor é um espaço de vazio teórico, possível em modelos como este, pois a combinação entre orientação alinhada ao status quo e postura antagônica resulta em uma contradição em si, gerando, portanto, ausência de exemplos.

Essa gradação de políticas externas periféricas em relação ao centro de poder requer, necessariamente, uma maior reflexão e detalhamento sobre cada uma dessas variaçôes, o que é feito a seguir.

Alinhamento automático. Trata-se do relacionamento mais estreito que um Estado, nesse caso periférico, pode ter com a potência dominante. Tal comportamento se reflete tanto na esfera bilateral quanto na regional e multilateral, onde todos os interesses da potência são apoiados de forma automática pelo Estado em questão. Tal postura, considerada subserviente por muitos e de redução da soberania, é pouco verificada e quase sempre quando é adotada tem como justificativas questões de ordem sistêmicas e não pontuais. A política de "relações carnais", termo cunhado pelo presidente argentino Carlos Menem na década de 1990 para descrever as relaçôes de seu governo com os Estados Unidos, é exemplo, ainda que curto, de um alinhamento automático de Buenos Aires em relação a Washington. A Venezuela do Pacto de Punto Fijo (1958-1998) ${ }^{1}$ adotou tal postura em poucos momentos e por curtos períodos, especialmente no início dos anos 1960, apenas por alguns meses durante a implementação da Doutrina Betancourt, e, na década de 1990, em breve período do segundo mandato do presidente Carlos Andrés Pérez.

Alinhamento sob condições. Apesar de ser uma forma menos radical de alinhamento com a grande potência, o alinhamento sob condiçôes é, a rigor, um alinhamento. No entanto, a postura de proximidade com a potência não

1 Pacto de conciliação de elites que pôs fim a um longo período de ditaduras militares na Venezuela, e que foi marcado por quatro décadas de alternância de poder pela via eleitoral por dois grandes partidos de centro-direita: Ação Democrática (AD) e o Comitê de Organização Eleitoral Independente (Copei). 
se baseia - ou não exclusivamente - apenas em vantagens sistêmicas a partir de uma consciência da assimetria, mas busca vantagens e contrapartidas imediatas. O apoio, nesse caso, é usado como moeda de troca, nas mais diferentes questôes, desde apoio político em questôes regionais e contenciosos, passando pelo comércio, cooperação técnica, até a ajuda financeira ou militar direta. Praticamente todos os países sul-americanos já tiveram seus momentos de alinhamento sob condições em relação aos Estados Unidos. Nos anos 1990, a maior parte deles, incluindo o Brasil, adotou esse tipo de posicionamento.

Política Externa Independente (PEI). Trata-se, aqui, de conceituação mais complexa, especialmente em virtude de o termo ser aplicado de forma histórica no Brasil para um determinado momento de sua política externa. A PEI, como é conhecida nos estudos de política externa do Brasil, é o nome pelo qual ficaram conhecidas as políticas externas dos governos de Jânio Quadros e João Goulart, que tinham como princípio básico uma atuação independente do País frente à bipolaridade entre as duas grandes potências, Estados Unidos e União Soviética, durante a Guerra Fria. O objetivo era proporcionar ao País os benefícios econômicos e políticos dessa postura independente.

A política externa independente do período pós-neoliberal não vê no alinhamento um instrumento para a obtenção de vantagens. Mas também não tem como objetivo implementar revisão de relações de fato. Trata-se de uma política intermediária entre o alinhamento sob condiçóes e o revisionismo autônomo. $\mathrm{O}$ autointeresse é priorizado, está acima dos interesses da potência, mas não converge com a ideia de que sua preservação prescinde de uma revisão de relações com os Estados Unidos e nem de mudanças substanciais do sistema internacional.

Os governos de Michelle Bachelet, no Chile, e de Alan Garcia, no Peru, foram os que mais se aproximaram desse modelo de política externa. Se não foram típicos governos alinhados aos Estados Unidos, é certo que também não adotaram políticas revisionistas como o de alguns países vizinhos, nem mesmo de forma moderada.

Revisionismo autônomo moderado. A política revisionista implica necessariamente uma mudança de foco nas relaçôes com a potência dominante, no caso os Estados Unidos. Trata-se, como citado anteriormente, de política que vê na mudança de sistema, da unipolaridade para a multipolaridade, requisito essencial para a defesa de seus interesses. Mas não se trata de uma política uniforme em todos os países onde foram ou são implementadas. As diferentes gradações fazem parte de uma sintonia fina importante para se entender a dinâmica das relações regionais com Washington.

O revisionismo autônomo tem como prioridade uma mudança de status quo do sistema internacional, mas trata-se de uma política de longo prazo, geralmente não explícita em retórica, mas com relativa atividade no plano político e intergovernamental. Não implica rompimento, pelo contrário, pode inclusive 
aceitar um maior intercâmbio com a potência. Mas trabalha intensamente pela redução da dependência, aumentando as relações com parceiros alternativos e diversificando as pautas política e comercial. $\mathrm{O}$ revisionismo autônomo atua sempre em dois níveis. Não busca a confrontação, mas trabalha pela diluição do poder, sempre que possível; coopera, mas busca também alternativas; não tem problemas em convergir em determinadas temáticas, mas está sempre vigilante em relação aos interesses da potência, mesmo quando estes são convergentes com os seus.

O revisionismo autônomo moderado é a primeira gradação das políticas revisionistas. Trata-se de uma política mais forte que a política externa independente, mas em tom sutilmente mais leve que o revisionismo autônomo forte. Nesse caso, o aproveitamento das "benesses do tempo" é ainda mais dilatado.

As políticas externas dos governos Lula e Dilma, no Brasil, são os exemplos mais notórios do revisionismo autônomo moderado, o que será detalhado mais a frente. Os dois governos pós-neoliberais do Uruguai, o de Tabaret Vázquez e o de José Mujica, também se aproximam do modelo revisionista mais moderado.

Revisionismo autônomo forte. Tem as mesmas características do revisionismo autônomo moderado. No entanto, é mais ativo especialmente na retórica sobre a necessidade de revisão de relações. Também é mais ativo no estabelecimento de relaçôes alternativas de poder e nos fóruns intergovernamentais. Tem um tempo um pouco mais acelerado que o revisionismo moderado, deseja mudanças mais rápidas e, por conta disso, tem postura menos discreta. Trata-se de política autônoma e não antagônica, a priori, mas que desperta maior atenção, sem dúvida, por parte da grande potência, por estar na fronteira entre a postura autônoma e a antagônica.

Os governos argentinos dos presidentes Néstor Kirchner e Cristina Kirchner, e algumas fases do governo venezuelano de Hugo Chávez são os maiores exemplos de um revisionismo autônomo forte.

Revisionismo antagônico forte. A postura antagônica possui diferenças de gradação importantes para uma orientação revisionista. Ao contrário do autonomismo, o antagonismo vê na confrontação um de seus principais instrumentos de revisão. Trata-se de uma política que não tem a pretensão de ser discreta. Busca especialmente na retórica de confrontação seu meio de atuação mais visível, com o claro objetivo de promover uma política de prestígio às avessas, em que os resultados benéficos não vêm do alinhamento, mas de uma política sistemática de oposição.

Uma política de oposição não vê a possibilidade de convergência, salvo raras exceçôes, e o trabalho no campo multilateral é sistematicamente orientado a divergir das posturas da potência. A aproximação de eixos alternativos de poder no plano político, mesmo que não aconteça da mesma forma no plano econômico, é feita de forma mais rápida e intensa que na política autônoma. Não existe a preocupação com a discrição, o que faz com que as blindagens contra eventuais retaliaçôes venham de uma radicalização de posições. Não se trata aqui de um 
rompimento total ou de uma situação de guerra, apesar de essas duas hipóteses quase sempre serem postas à mesa no campo retórico.

Seria contraditório denominar um antagonismo como moderado. Uma orientação antagônica é forte por sua própria postura de confrontação e oposição. Por isso mesmo é o lado mais conhecido das políticas revisionistas periféricas, apesar de sua ocorrência na primeira década do período pós-neoliberal ser muito menor que as posturas autônomas. A fase do governo Chávez entre 2002 e 2009, e fases dos governos Evo Morales, da Bolívia (2007-2009), e Rafael Correa, do Equador (2008-2009) são as três políticas que podem ser consideradas antagônicas fortes em relação aos Estados Unidos nesse período de 13 anos.

Revisionismo antagônico extremo. É o lado mais intenso de uma política de revisão antagônica. Marcada pelo alto nível de tensão permanente entre a potência e o país periférico e onde a ameaça de intervenção e de conflito são muito maiores que no antagonismo forte. A política de oposição, apesar de ter as mesmas características do antagonismo forte, ganha contornos mais ativos por conta de uma retórica ainda mais inflamada. Neste caso, o campo econômico pode ser marcado por uma redução considerável da cooperação e do comércio e até mesmo por embargos capazes de prejudicar fortemente a economia. O revisionismo antagônico extremo seria o último passo antes do rompimento de relações.

Não existem exemplos de governos progressistas sul-americanos que na última década tenham adotado esse tipo de revisionismo antagônico. Tal modelo é relevante, no entanto, para enfatizar que mesmo as políticas antagônicas de Venezuela, Bolívia e Equador nunca alcançaram níveis de confrontações que permitissem esse nível de tensão com os Estados Unidos. Trata-se de característica importante em uma avaliação geral sobre as políticas revisionistas sul-americanas.

A conceituação de diferentes orientações, posturas e gradaçôes de políticas revisionistas permite a classificação das políticas externas dos governos sulamericanos do período pós-neoliberal, progressistas ou não, a partir dessas características. Tal classificação é ilustrada na Tabela 1. 


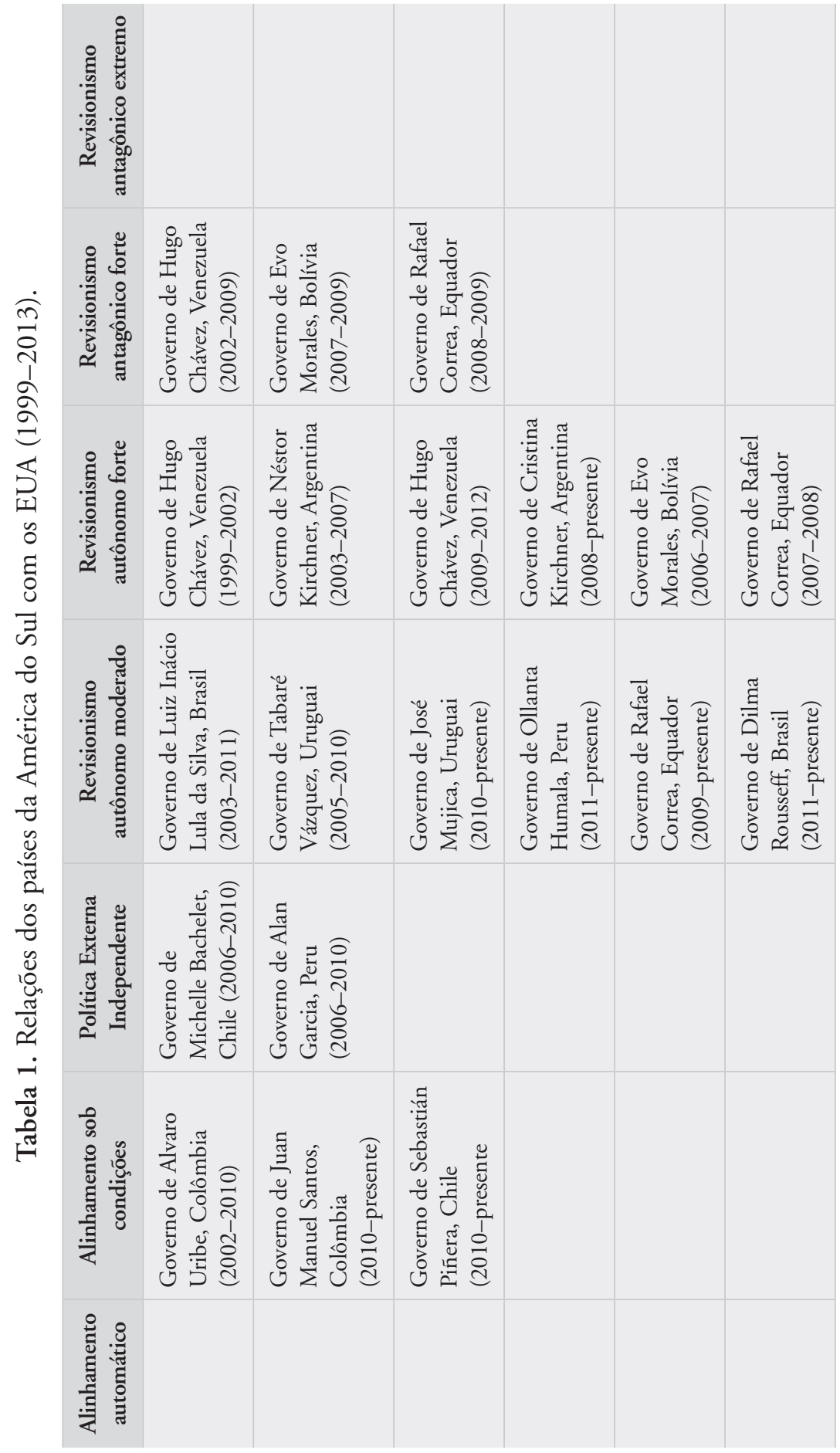




\section{Panorama geral das políticas revisionistas}

O período após os anos marcados pelo neoliberalismo, e especialmente após os atentados de 11 de Setembro, é marcado pela ausência de políticas externas alinhadas automaticamente aos Estados Unidos, diferentemente do que aconteceu durante quase toda a década de 1990, onde pelo menos Argentina e Venezuela tiveram fases marcadas por este tipo de relação. A conjuntura regional e o reposicionamento da política externa dos Estados Unidos na primeira década do século 21 - especialmente a Doutrina Bush e o notório afastamento de seu Hemisfério - provocaram o fim desse tipo de comportamento em relação à potência norte-americana no período.

Apenas três governos sul-americanos, dois colombianos e um chileno, mantiveram ou mantêm uma política de alinhamento sob condiçôes. Os dois governos colombianos do período, Alvaro Uribe (2002-2010), e Juan Manuel Santos (2010-presente), e o atual governo chileno do presidente Sebastián Piñera (2010-presente). A Colômbia é tradicional aliada dos Estados Unidos na região, em uma relação que se fortaleceu nos anos 1990, especialmente após a Operação Colômbia para o combate ao narcotráfico e aos guerrilheiros das Forças Armadas Revolucionárias da Colômbia (Farc). A luta contra o narcotráfico, bem-sucedida do ponto de vista dos governos colombianos, a pacificação de áreas urbanas importantes do país, como a capital Bogotá e a retomada de territórios onde o estado por décadas perdeu o controle foram relacionados diretamente por setores conservadores colombianos à ajuda norte-americana e o estreitamento de relaçóes foi colocado como o principal instrumento para a resolução dos problemas internos do país.

Sob o ponto de vista dos Estados Unidos, a Colômbia é um importante território sul-americano em meio a países com políticas revisionistas, com maior ou menor intensidade, e a manutenção de relações estreitas com Bogotá é justificada tanto por motivos geopolíticos quanto por de estratégia e atuação na região. A Colômbia, portanto, em nenhum momento do período pós-neoliberal demonstrou distanciamento ou mesmo uma política mais independente em relação ao seu maior aliado.

Se a Colômbia se comportou como o porto seguro norte-americano no campo da política, o Chile desde os anos 1970 é considerado como o grande exemplo das políticas e práticas econômicas agradáveis aos Estados Unidos. Tanto durante a ditadura de Pinochet quanto após o regime militar, quando o país foi considerado baluarte das reformas liberais na região, sendo apontado como "tigre sul-americano", numa analogia ao progresso pelo qual passaram os países do Sudeste Asiático. O período de presidência de Michelle Bachelet foi considerado um hiato, ainda que brando. Com suas políticas sociais no campo interno e com uma política externa não alinhada aos interesses norte-americanos, apesar de não revisionistas, 
o governo Bachelet permitiu que o Chile aprofundasse suas relações regionais e integrasse de maneira ativa projetos de relevância para os governos progressistas, como a UNASUL. No entanto, após o fim de seu governo e a vitória da direita nas eleições, representada por Sebastián Piñera, o país voltou a seu padrão de política externa dos últimos anos, que é o do alinhamento sob condições.

As políticas externas revisionistas em relação aos Estados Unidos foram as mais adotadas na América do Sul na primeira década do século 21 e, entre elas, a postura autônoma foi a preponderante. O revisionismo antagônico ocorreu, mas de forma pontual e em apenas três países: Venezuela, entre 2002 e 2009, Bolívia, entre 2007 e 2009, e Equador, entre 2008 e 2009. O caso venezuelano, o mais emblemático e influenciador do antagonismo boliviano e equatoriano, será discutido mais à frente. As fases antagonistas de Bolívia e Equador, assim como no caso da Venezuela, também tiveram em crises de repercussão externa os principais motivos para a guinada antagônica. No caso da Bolívia, as tentativas de autonomia da região da Meia Lua e as acusações de participação norte-americana no processo, e, no caso do Equador, a invasão de forças colombianas para o ataque em território equatoriano contra o acampamento de Raul Reyes, importante líder das Farc. Na visão do governo de Quito, tal ação teve amplo apoio norte-americano. Devido às condicionantes tanto da Bolívia quanto do Equador, bem diferentes da Venezuela, o período antagônico de ambos foi curto. Mas o revisionismo de relaçôes continuou, seja de forma autônoma moderada ou mais forte.

O revisionismo autônomo ocorreu de forma moderada nos dois governos do Brasil - Lula da Silva e Dilma Rousseff - e nos dois governos uruguaios - Tabaret Vázquez e José Mujica -, além do governo peruano de Ollanta Humala e na fase do governo equatoriano de Rafael Correa entre 2009 até o presente.

Já o revisionismo autônomo forte ocorreu no governo Hugo Chávez, da Venezuela, entre 1999 e 2002, nos governos argentinos de Néstor Kirchner e Cristina Kirchner, entre 2009 e 2012, no governo de Evo Morales, da Bolívia, entre 2006 e 2007, e de Rafael Correa, do Equador, entre 2007 e 2008.

Um melhor entendimento sobre as classificações utilizadas requer, necessariamente, análises mais detalhadas sobre as políticas revisionistas, principal foco deste trabalho. Diante da impossibilidade de uma análise de todos isoladamente, serão feitas a partir de agora análises separadamente dos casos de Venezuela e Brasil. A Venezuela configura-se como o principal caso de postura antagônica do período e o Brasil, por seu peso na região, o principal exemplo de revisionismo periférico autônomo.

\section{As fases autônoma e antagônica do governo Chávez}

A Venezuela foi precursora de uma onda de revisionismos de relaçóes com os Estados Unidos na região, questionando o modelo econômico imposto pelo Consenso de Washington, se distanciando politicamente do alinhamento quase 
automático com a Casa Branca e iniciando uma política externa de cunho mais autônomo a partir de 1999.

A presença de uma vizinhança ainda muito influenciada pelo momento unipolar pós-Guerra Fria e, no campo interno, a constatação de um país depauperado por quase 20 anos de crise econômica, por uma impressionante deterioração das condições sociais e pela necessidade - na visão do novo presidente - de rápida reforma política que desse suporte aos seus projetos, desembocaram em uma orientação externa nos primeiros momentos mais discreta, mas com postura claramente autônoma. Essa fase durou entre 1999 e 2002. Sua orientação era de uma política mais independente em relação aos Estados Unidos, especialmente na defesa dos preços internacionais do petróleo. $\mathrm{O}$ relacionamento com países como Iraque e Líbia era visto de forma pragmática, sem levar tanto em conta a rejeição americana, mas num movimento sem muita novidade, já que governos venezuelanos dos anos 1960 e 1970, em conjunturas distintas, adotaram políticas semelhantes. A relação comercial com os Estados Unidos, no entanto, não poderia sofrer revés. Muito pelo contrário, a necessidade de entrada de recursos para a execução de programas sociais e reformas exigia uma política comercial, especialmente em relação ao petróleo, austera e incentivadora da ampliação das vendas para seu principal mercado. Tratava-se de uma proposta de mudança de relaçóes de longo prazo, e que deveria ter o máximo de cuidado com a questão comercial, especialmente nos primeiros anos.

A guinada na orientação política aconteceu em 2002, motivada conjuntamente por fatores internos e externos. A tentativa frustrada de golpe contra o presidente, em abril de 2002, a paralisação da gigante estatal do petróleo PDVSA no final do mesmo ano, em outra tentativa articulada da oposição para derrubar o governo, e a convicção por parte de Caracas da participação norte-americana nesses dois eventos formaram um conjunto de fatores que, segundo Chávez, mereciam reaçôes mais enfáticas, para a sobrevivência do próprio governo. Nos planos regional e global, a emergência de governos com inclinação de esquerda, tanto no Cone Sul quanto nos países andinos e na América Central, e uma alta brutal dos preços do petróleo por quase uma década permitiram à Venezuela mudar de forma considerável sua conduta externa a partir de então. Após três anos de um revisionismo autônomo, portanto, o país inicia uma postura antagônica em relação a Washington, com a clara estratégia de evitar o que considerava como perigosas intervenções internas por parte dos norte-americanos.

Foi nesse momento que, no campo diplomático e acadêmico, se intensificou a construção teórica do revisionismo de relações venezuelano, com o objetivo de dar ao país fundamentos para uma atuação política de longo prazo que o distanciasse dos antigos alinhamentos com a grande potência. Já a diplomacia personalista do presidente entrou pelos caminhos da confrontação e do denuncismo, com o claro objetivo de mostrar que sofria graves ameaças por parte dos Estados Unidos. 
No plano político, o antagonismo começou a ser executado a partir do rápido aprofundamento das relações com a América Latina e, posteriormente, com outras regiōes como Oriente Médio e África, com tratamento especial dado a países considerados "párias" ou rivais estratégicos para os norte-americanos, como China, Rússia, Síria, Irã e Coreia do Norte. A defesa da multipolaridade ganhou ao mesmo tempo contornos panfletários e ações feitas a partir de três estratégias: acordos energéticos, compra de armas e política de integração regional.

A América Latina foi o grande bloco de apoio e de alianças para se evitar um isolamento regional da Venezuela provocado pelo distanciamento em relação aos Estados Unidos. Para isso, o país se baseou no uso dos recursos abundantes do petróleo para seduzir os vizinhos a um relacionamento mais estreito. Também priorizou a promoção de acordos de integração física e política, capazes de dar maior poder político a Caracas e tornar as alianças mais duradouras e com custos mais elevados de dissolução.

O período também foi marcado por uma grande aproximação política e econômica com a Bolívia do presidente Evo Morales, com o Equador de Rafael Correa, com a Nicarágua e especialmente com Cuba. A criação da Alternativa Bolivariana para as Américas (Alba), envolvendo esses países, foi uma resposta da Venezuela ao que considerava lentidão do processo de integração regional, e uma forma de tentar acelerar institucionalmente essa integração, diante dos entraves burocráticos e das resistências apresentadas dentro do Mercosul e da Unasul.

A aproximação de países considerados párias ou grandes rivais estratégicos dos Estados Unidos foi um dos reflexos da política antagônica do governo Chávez que mais teve impacto midiático, apesar de seus efeitos práticos terem sido bem mais limitados do que o propagado. Grande exportadora de armamentos, a Rússia tornou-se a melhor opção para a Venezuela diante do embargo de exportaçôes de produtos bélicos e aeronaves, imposto pelos Estados Unidos. Entre 2005 e 2007 a Venezuela firmou contratos no valor de US\$ 4 bilhões para a compra de caças, helicópteros e cerca de 100 mil fuzis Kalashnikov. Entre 2007 e 2010 a Venezuela ampliou suas compras de armamentos russos em mais de US\$ 2 bilhões. Foi também em 2008 que Venezuela e Rússia realizaram exercícios militares conjuntos no Caribe, num claro desafio venezuelano e russo ao governo do presidente americano George W. Bush.

Já os acordos com o Irã fizeram a Venezuela começar a exportar, a partir de 2009, 20 mil barris de gasolina por dia ao país, em uma tímida, mas emblemática, iniciativa de exportações de derivados de petróleo, já que o país até então praticamente exportava apenas o produto em seu estado bruto. O Irã, que tem poucas capacidades de refino, depende de importações para $40 \%$ de sua gasolina, o que tornou o país vulnerável a sanções ocidentais. Além disso, a PDVSA teve permissão para participar na exploração do campo iraniano de gás de Pars do Sul 12, um dos maiores do mundo. 
Também em 2008, após o presidente da Bolívia, Evo Morales, expulsar o embaixador americano em La Paz, acusado de ajudar na revolta separatista da região da Meia Lua, Chávez transformou a indisposição com os Estados Unidos em crise diplomática grave, expulsando do país o embaixador norte-americano em Caracas, Patrick Duddy, após acusá-lo de conspiração. O episódio provocou imediata reação da Casa Branca, que expulsou o embaixador venezuelano em Washington. As relaçôes políticas entre os dois países ficaram praticamente congeladas, mas apenas por 15 dias, até que novos embaixadores foram nomeados.

Essa fase antagônica do revisionismo venezuelano em relação aos Estados Unidos durou até 2009. A vitória de Barack Obama na corrida presidencial norte-americana provocou no governo Chávez uma forte disposição para a uma mudança de tom. Apesar de a política revisionista ter sido pouco impactada quanto aos seus fundamentos, a postura de confrontação conduzida por Chávez sofreu um forte revés nos primeiros meses. As crises diplomáticas, as acusações e os discursos inflamados deram lugar a declarações moderadas e em menor quantidade, apesar de uma reação pouco amistosa por parte do governo Obama. A crise econômica mundial de 2009, que provocou forte queda do preço do petróleo e consequentemente da receita do país, e, pouco tempo depois, a descoberta da grave doença do presidente ajudaram a compor o cenário do fim do período antagonista da política externa. O revisionismo autônomo forte, muito semelhante ao do período entre 1999 e 2002, passou a vigorar desde então.

Mesma política vem sendo adotada, até o momento, por seu sucessor, o presidente Nicolás Maduro. O pouco tempo de governo Maduro, no entanto, fez com que a política externa de seu governo não fosse analisada neste trabalho.

\section{O revisionismo periférico autônomo brasileiro: a moderação como marca}

"Queremos ter relações com os Estados Unidos, o que não podemos é nos tornar dependentes. Por isso, nos voltamos para a América Latina." A frase dita pelo ex-presidente Lula em conferência sobre política externa em São Paulo resume bem as diretrizes do Brasil após sua chegada ao poder, em 2003, em relação aos Estados Unidos: mudar as relações, sem mudar as impressões.

O Brasil governado por Lula foi alçado da condição de periferia para a de potência emergente, junto com um seleto grupo de países dos Bric. Ganhou respeito e reconhecimento internacionais por conta dos bem-sucedidos projetos de inclusão social e redução da pobreza, e por conta de uma fase de forte crescimento econômico. No campo externo, uma política presidencial de prestígio, calcada na

2 "Uma Nova Política Externa, Conferência Nacional", realizada na Universidade Federal do ABC, entre os dias 15 e 18 de julho de 2013. Disponível em <http://www.institutolula.org/lula-fala-dos-tres-eixos-da-politicaexterna-de-seu-governo-em-conferencia-na-ufabc/\#.Um_8LXBJOAg>. 
redução da fome como um dos principais pilares deu o molho necessário para que o País passasse a ser visto como grande promessa pela comunidade internacional. A ênfase dada na integração sul-americana também mostrou um Brasil mais próximo de seus vizinhos, e disposto a contribuir para a redução das assimetrias, estilo bem diferente do "urso brasileiro" dos anos 1990, interessado quase que exclusivamente no regionalismo aberto, o que abriu espaço para acusações não raras de sub-imperialismo.

As condicionantes do Brasil, os interesses estratégicos traçados pelo governo e o prestígio internacional de Lula tornaram inevitável o caminho do revisionismo de relações com os Estados Unidos. Mas o modelo de revisão adotado não era inevitável, e foi fruto da habilidade, tanto da diplomacia quanto do próprio presidente na conduçãao dessas relações.

A redução da dependência comercial com os Estados Unidos, a busca por parceiros e, consequentemente por mais influência, na América Latina, na África e na Ásia, e o uso dos projetos de integração sul-americana como plataforma de projeção internacional conjunta, deixaram claro o interesse do governo pela a projeção do Brasil como potência. Para isso, a existência de um sistema internacional multipolar, com mais distribuição de poder e com redução de assimetrias tornou-se fator sine qua non, mesmo que o discurso diplomático não desse tanta ênfase e este ponto, ao contrário do revisionismo antagônico venezuelano. Não se tratava, a priori, de estabelecer uma relação de confronto com os Estados Unidos, nem mesmo de gratuita indisposiçãoo (sempre que evitável, melhor) em uma busca deste objetivo, mas de estabelecer um jogo de dois níveis: cordialidade e cooperação no primeiro plano, pragmatismo e política estratégica no segundo. A diplomacia brasileira e o presidente sabiam que o momento era favorável para a intensificação de mudanças de natureza sistêmica, mas sem a necessidade de indisposições. Tratase, nesse caso, de um revisionismo autônomo, sem dúvida, mas com a moderação como marca.

No plano conceitual, o parâmetro de referência da política externa do Governo Lula passou a ser os experimentos passados da "Política Externa Independente", dos anos 60, e do "Pragmatismo Responsável", dos anos 70, com as adaptaçôes necessárias para fazer face à conjuntura internacional do início do século XXI. (Soares de Lima 2003, 51).

Mesmo a contraposição diplomática do Brasil necessária às posições norteamericanas - decorrente tanto dos objetivos nacionais quanto da revisão de relações - foi feita de forma efetiva, especialmente no plano multilateral, porém sem os efeitos colaterais de ações de confrontação direta. Até mesmo nos momentos onde a atuação da política externa brasileira claramente se direcionava contra os interesses do governo norte-americano, como no episódio do golpe de Estado em Honduras contra o presidente Manuel Zelaya, em 2009 (que pôs o Brasil como protagonista em uma área de influência estratégica e crucial para os Estados 
Unidos), a postura moderada brasileira influenciou a atuação norte-americana, que operou de forma ativa no plano político, mas evitou uma posição de confronto no plano retórico. Neste último, a atuação do Brasil no caso sempre foi considerada bem-vinda por parte da Casa Branca, enquanto no plano político e multilateral todos os esforços norte-americanos eram no sentido de manutenção do golpe de Estado, de não punição do novo governo hondurenho e, consequentemente, de demonstração de incapacidade do Brasil de contribuir de forma efetiva para a resolução de problemas na América Central.

A chegada da presidenta Dilma Rousseff ao poder resultou incialmente em uma política externa de continuidade em seus princípios básicos, porém de tom revisionista ainda mais moderado em relação aos Estados Unidos que o governo de seu antecessor. A mudança de postura no plano da diplomacia pública em relação ao Irã e a maior ênfase retórica sobre a temática dos direitos humanos representou um grau a mais de convergência aparente com o governo norte-americano. Isto não significou, no entanto, que o revisionismo estivesse posto de lado, por mais que alguns segmentos do Itamaraty claramente tenham entendido ou trabalhado nesse sentido.

As bases do revisionismo, a diminuição da dependência em relação aos Estados Unidos, a ênfase nas relações regionais e no eixo Sul-Sul não sofreram alteraçôes substanciais. Mas é fato, no entanto, que a diplomacia presidencial mais discreta da presidenta, e a liderança do Itamaraty pelo chanceler Antônio Patriota colaboram de forma substancial para uma impressão de moderação ainda mais forte que no governo anterior. A mudança de liderança no Ministério das Relações Exteriores e a reação da presidenta aos recentes episódios da espionagem norte-americana no Brasil, no entanto, sinalizam que o revisionismo brasileiro pode ganhar em 2014 um tom semelhante ou até mesmo um pouco mais forte que o adotado pelo governo Lula, ainda que com tendência a manter-se com um revisionismo autônomo.

\section{Considerações finais}

As relações da maior parte dos países sul-americanos com os Estados Unidos nos primeiros 13 anos do século 21, especialmente após a fase neoliberal na região e após os atentados de 11 de Setembro, passaram por alteraçôes substanciais. Apesar de os países sul-americanos tradicionalmente oscilarem entre momentos de alinhamento e fases de distanciamento em relação à grande potência do norte do continente, a onda recente de revisionismos, tanto pela quantidade de países quanto pelas consequências desses movimentos para as relações regionais e hemisféricas, merece devida atenção. Entre as características desse fenômeno, podemos destacar as seguintes.

Apesar de ter atingido a maior parte dos países sul-americanos no início deste século, e das muitas características em comum e convergências, o revisionismo 
de relações com os Estados Unidos não pode ser considerado um movimento uniforme. Possui diferentes posturas e gradaçôes, que variam conforme as estruturas e conjunturas de cada país. Compreender essas diferenças é, portanto, fator fundamental para um melhor entendimento sobre as relações presentes e futuras da região com os Estados Unidos, e também para compreender a atuação norte-americana no subcontinente.

A maior parte dos revisionismos periféricos implementados foi de postura autônoma e não antagônica. Os momentos antagônicos ocorreram em apenas três países (Venezuela, Equador e Bolívia) e, mesmo neles, de forma pontual (por períodos determinados de tempo), geralmente como reação a crises e posturas norte-americanas. Todas as fases antagônicas ocorreram durante o governo de George W. Bush e podem ser apontadas como uma reação à sua doutrina de política externa. Ou seja, se o revisionismo de relações com os Estados Unidos, em sentido amplo, é fruto das mudanças sistêmicas, o revisionismo antagônico foi uma resposta às políticas severas e muitas vezes de cunho intervencionista, ainda que não de forma direta, do governo Bush.

Os antagonismos sul-americanos, apesar do tom de confrontação, em nenhum momento chegaram a um ponto extremo, beirando a ruptura de relaçôes ou mesmo o conflito armado. As tensões diplomáticas mais sérias foram pontuais e nunca chegaram a ameaçar a estabilidade regional.

Países considerados chaves na região, Brasil e Argentina optaram por posturas autônomas e não antagônicas em seus revisionismos, ainda que a Argentina tenha adotado uma postura mais forte que a do Brasil. Tal opção de ambos foi fundamental para a manutenção de um bom nível de relação e entrosamento da região com os Estados Unidos, evitando indisposições e reações que pudessem comprometer a onda de mudanças de relacionamento.

O revisionismo periférico de relações foi um dos grandes motores dos movimentos de integração sul-americana, especialmente no Mercosul e na Unasul. A diminuição da dependência em relação aos Estados Unidos encontrou como caminho mais viável para a maioria dos países uma maior interdependência regional.

Mesmo que a fase dos governos progressistas sul-americanos se esgote, os resultados de mais de uma década de revisionismos de relações com os Estados Unidos são de difícil reversão pelo menos em curto e médio prazo. Os projetos de integração já realizados e em andamento, especialmente os estratégicos, a diversificação das relações dos países da região com o mundo (com a consequente diminuição da dependência em relação aos Estados Unidos), em conjunto com as modificações do sistema internacional, especialmente o maior papel da China no subcontinente, fazem com que as relações hemisféricas ganhem novos contornos e dinâmicas. Os Estados Unidos, sem dúvida, continuam como grande potência, possuem e continuarão possuindo crucial relevância na região e no mundo. Mas as mudanças de relações da América do Sul com a grande potência do Norte chegaram para ficar, pelo menos por um bom tempo. 


\section{Referências bibliográficas}

ALMEIDA, P. (2006). Uma nova "arquitetura" diplomática? Interpretações divergentes sobre a política externa do governo Lula (2003-2006). Revista Brasileira de Política Internacional, 49(1), 22.

BALESTRINI, Cesar C (1991). Economia y politica petrolera. Caracas: Ed.Academia Nacional. Fundación editorial universitaria de Venezuela.

CERVO, Amado (2001). Relaçóes Internacionais da América Latina: novos e velhos paradigmas. Brasília: FUNAG.

. (2003). A política exterior: de Cardoso a Lula. Revista Brasileira de Política Internacional, 46, 7.

CHÁVEZ, Hugo (2005). 1999: Año de la refundación de la república. Caracas: Ediciones de la Presidencia de la República.

COX, Robert (1983). Gramsci, hegemony and international relations: an essay in method. Journal of International Studies 12, pp-126-155.

ESCUDÉ, Carlos (1992). Realismo Periférico: Bases Teóricas para una Nueva Política Exterior Argentina, Buenos Aires: Planeta.

GALVÃO, Thiago G.. (2009). América do Sul: Construção pela reinvenção (2000-2008). Revista Brasileira de Politica Internacional, 52(2), 18.

GUIMARĀES, Cesar (2008). Integração Hemisférica ou Integração Autônoma. In: LIMA, Maria Regina Soares (org). Desempenho de governos progressistas do Cone Sul. Rio de Janeiro: Edições Iuperj, 2008.

HIRST, M. (1982). O Processo de Alinhamento nas Relações Brasil-Estados Unidos: 1942-1945. Dissertação de Mestrado, IUPERJ, Rio de Janeiro.

JAGUARIBE, Helio (1986). Autonomia Periférica e Hegemonia Cêntrica. O novo cenário internacional. Conjunto de Estudos. Rio de Janeiro: Guanabara.

(1988) A América Latina no presente contexto internacional. Revista Brasileira de Política Internacional. Ano XXXI, n 123, julho/dezembro.

. (2005) O Nacionalismo na Atualidade Brasileira. Rio de Janeiro: Ed. Universidade Candido Mendes.

KEOHANE, Robert (1984). After Hegemony. Princeton: Princeton University Press.

KRASNER, Stephen (1978). Defending the National Interest. Princeton: Princeton University.

KOZLOFF, Nikolas (2007). Hugo Chavez: Oil, politics, and the challenge to the U.S. New York: Palgrave Mcmillan.

LAFER, Celso; FONSECA, Gelson (1995). A Problemática da Integração num Mundo de Polaridades Indefinidas. In MARTINS, Guilherme d'Oliveira et al. A Integração Aberta - Um Projeto da União Europeia e do Mercosul. Lisboa: IEEI.

LAFER, Celso (2000). Brazilian International Indetity and Foreign Policy: Past, Present and Future. Daedalus, v. 129, n. 2.

LESSA, Antônio Carlos (2010). Brazil's strategic partnerships: an assessment of the Lula era (2003-2010). Rev. bras. polit. int., Brasília, vol 53, no. spe. 
MORGENTHAU, Hans (1948). Politics among Nations: The Struggle for Power and Peace. Chicago: University of Chicago Press.

PECEQUILO, Cristina. (2008). A política externa do Brasil no século XXI: Os eixos combinados de cooperação horizontal e vertical. Revista Brasileira de Política Internacional, 51(2), 136-153.

SARAIVA, Miriam. (2007). As estratégias de cooperação Sul-Sul nos marcos da política externa brasileira de 1993 a 2007. Revista Brasileira de Política Internacional, 50(2), 18.

SOARES DE LIMA, Maria Regina (org). Desempenho de governos progressistas do Cone Sul. Rio de Janeiro: Edições Iuperj.

. (2000). Instituições Democráticas e Política Exterior. Contexto Internacional. Vol. 22, n 2, julho/dezembro, pp 265-303.

. (2003). As Américas na Política Externa do Governo Lula. Anuario Social y Político de America Latina y Caribe, Año 6.

; COUTINHO, Marcelo V. (2006). Integração Moderna. Análise de Conjunta do Observatório Político Sul-Americano (OPSA), n1, janeiro.

Recebido em 11 de maio de 2014

Aprovado em 31 de maio de 2014

\section{Resumo}

Este artigo identifica e analisa os diferentes tipos de política revisionista, e suas gradações, desenvolvidos pelos governos progressistas da América do Sul em relação aos Estados Unidos nos últimos 13 anos. Para isso, tem como ponto de partida conceitos fundamentais para o melhor entendimento sobre o comportamento dos países da região em relação à grande potência: "revisionismo periférico", de Cesar Guimarães, e "confrontação autônoma" e "confrontação antagônica", ambos de Helio Jaguaribe. A partir dos desdobramentos desses conceitos foi desenvolvido um modelo teórico com diferentes tipos de revisionismos periféricos, o que permitiu uma espécie de sintonia fina de classificações das políticas externas do período.

Palavras-chave: América do Sul; Estados Unidos; governos progressistas; política externa; revisionismo.

\section{Abstract}

This paper identifies and analyzes the different types of revisionist politics, and its levels, developed by progressive governments in South America toward the United States over the past 13 years. For such, it uses as starting points concepts that are fundamental for better understanding the behavior of South American countries in relation with the great power: "peripheral revisionism," by Cesar Guimarães, and "autonomous confrontation" and "antagonistic confrontation," both by Helio Jaguaribe. From the developments of these concepts, a theoretical model was developed with different types of peripheral revisionisms, which allowed for fine-tuning the classifications of foreign policies in the period.

Keywords: South America; United States; progressive governments; foreign policy; revisionism. 